\title{
Comparison of fecal pyruvate kinase isoform M2 and calprotectin in assessment of pediatric inflammatory bowel disease severity and activity
}

\author{
Elzbieta Czub1, Jan K. Nowak², Anna Szaflarska-Poplawska3, Urszula Grzybowska- \\ Chlebowczyk ${ }^{4}$, Piotr Landowski ${ }^{5}$, Jerzy Moczko ${ }^{6}$, Daria Adamczak ${ }^{7}$ Przemyslaw Mankowski ${ }^{8}$, \\ Tomasz Banasiewicz ${ }^{9}$ Andrzej Plawski ${ }^{10}$ and Jaroslaw Walkowiak²
}

${ }^{1}$ Child \& Mother Specialist Hospital in Poznan, Poznań, Poland; 2Poznan University of Medical Sciences, Department of Pediatric Gastroenterology \& Metabolic Diseases, Poznań, Poland; ${ }^{3}$ Nicolaus Copernicus University, Ludwik Rydygier Collegium Medicum in Bydgoszcz, Department of Pediatric Endoscopy and Gastrointestinal Function Testing, Bydgoszcz, Poland; ${ }^{4}$ Medical University of Silesia, Department of Paediatrics, Katowice, Poland; ${ }^{5}$ Medical University of Gdansk, Department of Pediatrics, Pediatric Gastroenterology, Hepatology and Nutrition, Gdańsk, Poland; 'Poznan University of Medical Sciences, Department of Informatics and Statistics, Poznań, Poland; 7 Poznan University of Medical Sciences, Poznań, Poland; 'Poznan University of Medical Sciences, Department of Paediatric Surgery, Traumatology and Urology, Poznań, Poland; ${ }^{9}$ Poznan University of Medical Sciences, Department of General, Gastroenterological and Endocrinological Surgery, Poznań, Poland; ${ }^{10}$ nnstitute of Human Genetics, Polish Academy of Sciences, Poznań, Poland

\begin{abstract}
Aims: Accurate assessment of inflammatory bowel disease (IBD) activity is the cornerstone of effective therapy. Fecal M2 isoform of pyruvate kinase (M2-PK) and fecal calprotectin (FC) are noninvasive markers of mucosal inflammation in IBD. The aim of this study was to compare performance of M2-PK and FC in assessment of pediatric ulcerative colitis (UC) and Crohn's disease (CD) severity and activity. Materials and methods: 121 patients with IBD, including 75 with UC and 46 with CD were recruited. Control group consisted of 35 healthy children (HS). Patients were assigned to groups depending on disease severity and activity. M2-PK and calprotectin concentration were determined in stool samples using ELISA. Areas under receiver operating characteristic curves (AUC) for FC and M2-PK with cut-off level at which M2-PK specificity was matching FC specificity were calculated and compared. Results: Performance of M2-PK at identifying patients with IBD, UC and CD among HS was inferior to FC. The differences in AUC were respectively: -0.10 (95\% confidence interval $[\mathrm{Cl}][-0.13-(-0.06)], \mathrm{p}<0.0001)$, $-0.14(95 \% \mathrm{Cl}[-0.19-(-0.09)], \mathrm{p}<0.0001)$ and $-0.03(95 \%$ $\mathrm{Cl}[-0.05-(-0.001)], \mathrm{p}<0.02)$. M2-PK was inferior to $\mathrm{FC}$ in discriminating patients with mild UC from those with HS (AUC difference $-0.23,95 \% \mathrm{Cl}[-0.31-(-0.15)], \mathrm{p}<0.0001)$. Conclusions: FC reflects pediatric IBD severity and activity better than M2-PK. This difference is particularly pronounced when identifying patients with mild UC and UC in remission.
\end{abstract}

Key words: pyruvate kinase, calprotectin, inflammatory bowel diseases, ulcerative colitis, Crohn's disease, pediatrics

Received: 11 September, 2013; revised: 12 March, 2014; accepted: 16 March, 2014; available on-line: 20 March, 2014

\section{INTRODUCTION}

Embryonic M2 isoform of pyruvate kinase (M2-PK) is a cytosolic enzyme catalyzing a phosphate group transfer in glycolysis (Walkowiak et al., 2005). Its tetrameric and dimeric forms are present in proliferating cells of many tissues, including leukocytes (Gupta \& Bamezai, 2010). Upon leukocyte destruction in the gastrointestinal tract, the protein is released to the fecal stream (Walkowiak et al., 2005). M2-PK is stable in stools, which increases the potential value of fecal M2-PK concentration assessment both in intestinal inflammation and cancer. We postulated that fecal M2-PK could serve as a biomarker of inflammation in pediatric inflammatory bowel diseases (IBD) (Czub et al., 2007). Other groups concentrated on M2-PK utility in cancer diagnostics (Gupta \& Bamezai, 2010).

Calprotectin is a calcium and zinc binding protein belonging to S100 protein family. It constitutes more than $40 \%$ of neutrophil cytosol proteins and exhibits bacteriostatic activity (Yui et al., 2003). It has been shown that fecal calprotectin (FC) concentration correlates with severity of inflammatory bowel disease endoscopic presentation (Aomatsu et al., 2011; D'Haens et al., 2012; Önal et al., 2012). It is also known that fecal calprotectin may be used to predict IBD relapses (Lasson et al., 2013; Mao et al., 2012). Although calprotectin's sensitivity and specificity in adult IBD is $93 \%$ and $96 \%$ respectively, it was demonstrated that in children the specificity is significantly lower (van Rheenen et al., 2010).

To date two studies comparing M2-PK and calprotectin were published. In 2008 Shastri et al. described fecal M2-PK and FC concentrations in a population of 276 adult patients with IBD, concluding that M2PK had inferior specificity (Shastri et al., 2008). In 2010 Turner et al. investigated fecal M2-PK, FC, lactoferrin and S100A12 protein in children with severe ulcerative colitis (Turner et al., 2010). They showed that only M2-PK had constructive and predictive validity, while other markers failed to meet this criterion. Therefore the aim of this study was to compare the value of M2-PK and calprotectin in assessment of pediatric IBD activity.

e-mail: jarwalk@ump.poznan.p

Abbreviations: AUC, area under receiver operating characteristic curves; CD, Crohn's disease; ELISA, enzyme-linked immunosorbent assay; FC, fecal calprotectin; HS, healthy subjects; IBD, inflammatory bowel diseases; IQR, interquartile range; M2-PK, M2 isoform of pyruvate kinase; PCDAl, the Pediatric Crohn's Disease Activity Index; ROC, receiver operating characteristic; TW, Truelove-Witts; UC, ulcerative colitis 
Table 1. Group characteristics.

Data for age are presented as median (interquartile range). UC — ulcerative colitis, CD — Crohn's disease, HS — healthy subjects.

\begin{tabular}{|c|c|c|c|c|c|c|c|c|}
\hline & \multirow{2}{*}{$\begin{array}{l}\text { Number of } \\
\text { participants }\end{array}$} & \multicolumn{2}{|l|}{ Sex } & \multirow[b]{2}{*}{ Age, years } & \multicolumn{2}{|c|}{ Disease severity } & \multicolumn{2}{|c|}{ Disease activity } \\
\hline & & Male & Female & & Mild & $\begin{array}{l}\text { Moderate } \\
\text { and severe }\end{array}$ & Remission & Active \\
\hline UC & 75 & 44 (58.7\%) & 31 (41.3\%) & $\begin{array}{l}13.8 \\
(11.25-16.08)\end{array}$ & $\begin{array}{l}43 \\
(57.3 \%)\end{array}$ & 32 (42.7\%) & 40 (53.3\%) & $35(46.7 \%)$ \\
\hline$C D$ & 46 & 28 (60.9\%) & 18 (39.1\%) & $\begin{array}{l}15.4 \\
(12.92-16.33)\end{array}$ & $\begin{array}{l}25 \\
(54.3 \%)\end{array}$ & $21(45.7 \%)$ & 22 (47.8\%) & $24(52.2 \%)$ \\
\hline HS & 35 & 18 (51.4\%) & 17 (48.6\%) & $\begin{array}{l}15.0 \\
(11.3-16.0)\end{array}$ & & & & \\
\hline
\end{tabular}

\section{MATERIALS AND METHODS}

One hundred fifty-six children were enrolled for the study, including 75 with ulcerative colitis (UC), 46 with Crohn's disease (CD) and 35 healthy controls (HC). The diagnosis of IBD was based on the physical examination, endoscopic, histologic and radiologic evaluations, as well as supplementary laboratory tests (Kornbluth et al., 2004; Turner et al., 2007; Van Assche et al., 2010). Disease severity was described using Truelove-Witts (TW) scores in children with ulcerative colitis (Mahadevan et al., 2002) (Kobelska-Dubiel et al., 2007) and The Pediatric Crohn's Disease Activity Index (PCDAI) in Crohn's disease patients (Hyams et al., 1991). Whether disease was active or in remission was determined on basis of an extended set of criteria including endoscopy, magnetic resonance enterography, ultrasonography and biomarkers of inflammation in the blood, depending on the case studied and the clinical context. Group characteristics are presented in Table 1. Median TW score was 1.0 (interquartile range [IQR]: 0-5), median PCDAI score was 42.5 (7-60).

The study was conducted in four tertiary care centres and one secondary care centre. Fresh stool samples were initially stored at 4 degrees Celsius and at -70 degrees Celsius after transfer to the laboratory. Dimeric M2-PK concentration was assessed using commercially available sandwich ELISA with monoclonal antibodies (ScheBo Biotech, Giesen, Germany) and expressed in U/g. Although manufacturer-suggested cut-off value was $4 \mathrm{U} / \mathrm{g}$, results for cut-off set at $5 \mathrm{U} / \mathrm{g}$ were analysed as well to increase the test specificity. FC levels were determined employing PhiCal ELISA Test (Calpro, Lysaker, Norway). Cut-off concentration for FC was $15 \mu \mathrm{g} / \mathrm{mL}$. Both analyses were performed in the same stool specimens. All samples were assessed by the same observer who was unaware of group allocation.

Statistical analysis was carried out using STATISTICA data analysis software system v. 10 (StatSoft, Inc., Tulsa, United States of America) and Analyse-it v. 2.30 (Analyse-it Software, Leeds, United Kingdom). Sensitivity, specificity and area under receiver operating characteristic (ROC) curve were calculated. The areas under the receiver operating characteristic curves (AUC) for M2-PK and FC in different settings were compared. These comparisons were made after adjusting M2-PK cut-off level so that M2-PK specificity equaled that of FC at standard cut-off value of 15 . M2-PK and FC performance was compared with the use of Whitney-Mann U-test. The level of significance was set at $\mathrm{p}<0.05$. The data are presented as median (IQR), unless stated otherwise.

Parents of all patients, and patients at least 16 years old have expressed their written, informed consent to participation in the study. The study project received a positive opinion of the Bioethical Committee at Poznan University of Medical Sciences (decision 1740/04).

\section{RESULTS}

Fecal concentrations of M2-PK and FC in groups are shown in Table 2. The highest M2-PK concentration was $1849.0 \mathrm{U} / \mathrm{g}$, while the highest FC concentration was $556.0 \mu \mathrm{g} / \mathrm{mL}$, both in active, severe UC. Highest concentrations of M2-PK and FC in patients with CD was $770.4 \mathrm{U} / \mathrm{g}$ (mild CD in remission) and $456.0 \mu \mathrm{g} / \mathrm{mL}$ (active, severe $\mathrm{CD}$ ), respectively.

Fecal concentrations of M2-PK and FC in subgroups of children with IBD depending on disease activity status and disease severity are shown in Table 3. and Table 4.

The performance of M2-PK in distinguishing UC patients from those with HS was inferior to FC (AUC difference $-0.14,95 \%$ confidence interval [CT] [-0.19$(-0.09)], \mathrm{p}<0.0001)$. M2-PK was also inferior to FC in distinguishing $\mathrm{CD}$ patients from $\mathrm{HS}$ (AUC difference $-0.03,95 \%$ CI $[-0.05-(-0.001)], \mathrm{p}<0.02)$. In general, the performance of M2-PK in identifying patients with IBD among HS was poorer in comparison with FC (AUC difference $-0.10,95 \%$ CI [-0.13-(-0.06)], p <0.0001). M2-PK

Table 2. Fecal concentrations of pyruvate kinase isoform M2 (M2-PK) and calprotectin (FC) in groups.

Data are presented as median (interquartile range). CD - Crohn's disease, HS - healthy subjects, IBD - inflammatory bowel disease, UC - ulcerative colitis.

\begin{tabular}{lllll}
\hline & \multicolumn{2}{l}{ M2-PK, U/g } & \multicolumn{2}{l}{$\mathrm{FC}, \mu \mathrm{g} / \mathrm{mL}$} \\
\hline HS & 0 & $(0.0-1.3)$ & 2.5 & $(2.0-2.5)$ \\
\hdashline IBD & 22.0 & $(2.4-194.2)$ & 56.0 & $(12.5-218.0)$ \\
\hline UC & 10.0 & $(0.6-189.5)$ & 45.0 & $(11.8-211.0)$ \\
\hdashline CD & 63.5 & $(12.9-182.8)$ & 78.0 & $(25.2-212.0)$ \\
\hline
\end{tabular}

Table 3. Fecal concentrations of pyruvate kinase isoform M2 (M2-PK) and calprotectin (FC) in groups of children with inflammatory bowel diseases depending on activity status.

Data are presented as median (interquartile range). A - active, CD - Crohn's disease, R - remission, UC - ulcerative colitis.

\begin{tabular}{ccccc}
\hline & \multicolumn{2}{l}{ M2-PK, U/g } & \multicolumn{2}{l}{$\mathrm{FC}, \mu \mathrm{g} / \mathrm{mL}$} \\
\hline UC-R & 1.5 & $(0.0-7.1)$ & 12.5 & $(5.0-32.9)$ \\
\hdashline UC-A & 148.8 & $(12.3-375.1)$ & 176.0 & $(88.5-329.5)$ \\
\hdashline CD-R & 32.6 & $(5.0-76.8)$ & 29.0 & $(12.5-71.2)$ \\
\hdashline CD-A & 96.3 & $(23.9-200.2)$ & 189.5 & $(74.8-275.0)$ \\
\hline
\end{tabular}


Table 4. Fecal concentrations of pyruvate kinase isoform M2 (M2-PK) and calprotectin (FC) in children with inflammatory bowel diseases depending on disease severity.

Data are presented as median (interquartile range). CD - Crohn's disease, $\mathrm{M}-$ mild, UC - ulcerative colitis, $\mathrm{S}-$ moderate to severe.

\begin{tabular}{ccccc}
\hline & \multicolumn{2}{l}{ M2-PK, U/g } & \multicolumn{2}{l}{$\mathrm{FC}, \mu \mathrm{g} / \mathrm{mL}$} \\
\hline UC-M & 1.95 & $(0.0-10.0)$ & 12.5 & $(5.0-88.2)$ \\
\hdashline UC-S & 152.9 & $(26.6-408.3)$ & 187.5 & $(52.7-334.2)$ \\
\hdashline CD-M & 40.2 & $(7.8-200.2)$ & 32.5 & $(12.5-80.0)$ \\
\hdashline CD-S & 96.3 & $(20.8-130.7)$ & 167.0 & $(78.0-256.0)$ \\
\hline
\end{tabular}

was less efficacious than FC in discriminating patients with mild CU from HS (AUC difference $-0.23,95 \%$ CI $[-0.31-(-0.15), \mathrm{p}<0.0001]$ and patients with mild $\mathrm{CD}$ from HS $(-0.04,95 \%$ CI $[-0.08-(-0.01)], \mathrm{p}=0.025)$. M2PK was inferior to FC in identifying patients with UC in remission among HS (AUC difference - $0.22,95 \%$ CI $[-0.30-(-0.14)], \mathrm{p}<0.0001)$ and patients with $\mathrm{CD}$ in remission among HS (AUC difference -0.05, 95\% CI (-0.09$(-0.01), \mathrm{p}=0.02)$.

\section{DISCUSSION}

This is the first study to directly compare M2-PK and FC in assessment of severity and activity of pediatric IBD. It presents a response to questions that arose after we found that M2-PK is a marker of pediatric IBD activity (Czub et al., 2007). The main concern was to determine whether M2-PK could improve IBD diagnostics in children.

The data obtained lend support to the notion that $\mathrm{M} 2-\mathrm{PK}$ is inferior to FC in IBD diagnostics. This was clearly visible in two areas: identification of UC patients among HS and recognition of UC patients in remission among HS. Both were expressed in marked AUC differences. With regard to $\mathrm{CD}$, the AUC differences were smaller, yet significant. Given the high sensitivity and good specificity of FC, M2-PK would present no added value in CD (Henderson et al., 2013).

In general, observations regarding FC that were made in this study are in line with what was previously described (Bunn et al., 2001; Komraus et al., 2012; Kostakis et al., 2013). They seem to contradict the conclusions drawn by Shaoul et al. who found no correlation between clinical IBD activity and FC concentrations (Shaoul et al., 2012) and to agree with a report by D'Haens et al. in which a correlation between clinical score in UC and FC was described (D'Haens et al., 2012).

One of the limitations of this study is that it investigated M2-PK and FC in the context of disease severity and activity without detailed analysis of response to treatment in a longer period of observation. This was rendered impossible by the settings.

The future directions of research should include questions, such as: how fecal markers could be used to decrease the number of endoscopic investigations without compromising diagnosis (Aomatsu et al., 2011; van Rheenen et al., 2010), to predict relapses in patients that do not exhibit symptoms (Kallel et al., 2011; Mao et al., 2012), and to predict the course of disease in general (Lasson et al., 2013; Önal et al., 2012).
In conclusion, these data show that in children, calprotectin reflects IBD severity and activity better than M2-PK.

\section{Acknowledgements}

This research was supported by a grant from Poznan University of Medical Sciences.

\section{REFERENCES}

Aomatsu T, Yoden A, Matsumoto K, Kimura E, Inoue K, Andoh A, Tamai H (2011) Fecal calprotectin is a useful marker for disease activity in pediatric patients with inflammatory bowel disease. Dig Dis Sci 56: 2372-2377.

Bunn SK, Bisset WM, Main MJ, Golden BE (2001) Fecal calprotectin as a measure of disease activity in childhood inflammatory bowel disease. J Pediatr Gastroenterol Nutr 32: 171-177.

Czub E, Herzig KH, Szaflarska-Popławska A, Kiehne K, Socha P, Woś H, Kaminska B, Błaszczynski M, Cichy W, Bała G, Brodzicki J, Grzybowska-Chlebowczyk U, Walkowiak J (2007) Fecal pyruvate kinase: a potential new marker for intestinal inflammation in children with inflammatory bowel disease. Scand J Gastroenterol 42: 1147-1150.

D'Haens G, Ferrante M, Vermeire S, Baert F, Noman M, Moortgat L, Geens P, Iwens D, Aerden I, Van Assche G, Van Olmen G, Rutgeerts P (2012) Fecal calprotectin is a surrogate marker for endoscopic lesions in inflammatory bowel disease. Inflamm Bowel Dis 18: 2218-2224

Gupta V, Bamezai RNK (2010) Human pyruvate kinase M2: a multifunctional protein. Protein Sci Publ Protein Soc 19: 2031-2044.

Henderson P, Anderson NH, Wilson DC (2013) The Diagnostic Accuracy of Fecal Calprotectin During the Investigation of Suspected Pediatric Inflammatory Bowel Disease: A Systematic Review and Meta-Analysis. Am J Gastroenterol (online ahead of print).

Hyams JS, Ferry GD, Mandel FS, Gryboski JD, Kibort PM, Kirschner BS, Griffiths AM, Katz AJ, Grand RJ, Boyle JT (1991) Development and validation of a pediatric Crohn's disease activity index. $J$ Pediatr Gastroenterol Nutr 12: 439-447.

Kallel L, Fekih M, Boubaker J, Filali A (2011) [Faecal calprotectin in inflammatory bowel diseases: review.] Tunis Médicale 89: 425-429.

Kobelska-Dubiel N, Ignyś I, Cichy W, Kobelski M (2007) Clinical indices in inflammatory bowel diseases in children. Pediatria Współczesna. Gastroenterologia, Hepatologia i Żywienie Dziecka, 9: 167-171.

Komraus M, Wos H, Wiecek S, Kajor M, Grzybowska-Chlebowczyk U 2012 Usefulness of faecal calprotectin measurement in children with various types of inflammatory bowel disease. Mediators Inflamm 2012: 608249 .

Kornbluth A, Sachar DB, Practice Parameters Committee of the American College of Gastroenterology (2004) Ulcerative colitis practice guidelines in adults (update): American College of Gastroenterology Practice Parameters Committee. Am J Gastroenterol 99: 1371-1385.

Kostakis ID, Cholidou KG, Vaiopoulos AG, Vlachos IS, Perrea D, Vaos G (2013) Fecal calprotectin in pediatric inflammatory bowel disease: a systematic review. Dig Dis Sci 58: 309-319.

Lasson A, Simrén M, Stotzer PO, Isaksson S, Ohman L, Strid H (2013) Fecal calprotectin levels predict the clinical course in patients with new onset of ulcerative colitis. Inflamm Bowel Dis 19: 576-581.

Mahadevan U, Loftus EV Jr, Tremaine WJ, Pemberton JH, Harmsen WS, Schleck CD, Zinsmeister AR, Sandborn WJ (2002) Azathioprine or 6-mercaptopurine before colectomy for ulcerative colitis is not associated with increased postoperative complications. Inflamm Bowel Dis 8: 311-316.

Mao R, Xiao Y, Gao X, Chen B, He Y, Yang L, Hu P, Chen M (2012) Fecal calprotectin in predicting relapse of inflammatory bowel diseases: a meta-analysis of prospective studies. Inflamm Bowel Dis 18: 1894-1899.

Önal İK, Beyazit Y, Șener B, Savuk B, Özer Ettk D, Sayilir A, Öztaş E, Torun S, Özderın Özın Y, Tunç Demırel B, Ülker A, Dağli Ü (2012) The value of fecal calprotectin as a marker of intestinal inflammation in patients with ulcerative colitis. Turk J Gastroenterol Off J Turk Soc Gastroenterol 23: 509-514.

Shaoul R, Sladek M, Turner D, Paeregaard A, Veres G, Wauters GV, Escher J, Dias JA, Lionetti P, Staino A, Kolho KL, de Ridder L, Nuti F, Cucchiara S, Sheva O, Levine A, ESPGHAN Porto IBD Group (2012) Limitations of fecal calprotectin at diagnosis in untreated pediatric Crohn's disease. Inflamm Bowel Dis 18: 1493-1497.

Shastri YM, Povse N, Schröder O, Stein J (2008) Comparison of a novel fecal marker--fecal tumor pyruvate kinase type M2 (M2-PK) with fecal calprotectin in patients with inflammatory bowel disease: a prospective study. Clin Lab 54: 389-390. 
Turner D, Leach ST, Mack D, Uusoue K, McLernon R, Hyams J, Leleiko N, Walters TD, Crandall W, Markowitz J, Otley AR, Griffiths AM, Day AS (2010) Faecal calprotectin lactoferrin M2-pyruvate kinase and S100A12 in severe ulcerative colitis: a prospective multicentre comparison of predicting outcomes and monitoring response. Gut 59: 1207-1212.

Turner D, Otley AR, Mack D, Hyams J, de Bruijne J, Uusoue K, Walters TD, Zachos M, Mamula P, Beaton DE, Steinhart AH, Griffiths AM (2007) Development validation and evaluation of a pediatric ulcerative colitis activity index: a prospective multicenter study. Gastroenterology 133: 423-432.

Van Assche G, Dignass A, Panes J, Beaugerie L, Karagiannis J, Allez M, Ochsenkühn T, Orchard T, Rogler G, Louis E, Kupcinskas L, Mantzaris G, Travis S, Stange E, European Crohn's and Colitis
Organisation (ECCO) (2010) The second European evidence-based Consensus on the diagnosis and management of Crohn's disease: Definitions and diagnosis. J Crobns Colitis 4: 7-27.

Van Rheenen PF, Van de Vijver E, Fidler V (2010) Faecal calprotectin for screening of patients with suspected inflammatory bowel disease: diagnostic meta-analysis. BMJ 341: c3369-c3369.

Walkowiak J, Banasiewicz T, Krokowicz P, Hansdorfer-Korzon R, Drews M, Herzig KH (2005) Fecal pyruvate kinase (M2-PK): a new predictor for inflammation and severity of pouchitis. Scand J Gastroenterol 40: 1493-1494.

Yui S, Nakatani Y, Mikami M (2003) Calprotectin (S100A8/S100A9) an inflammatory protein complex from neutrophils with a broad apoptosis-inducing activity. Biol Pharm Bull 26: 753-760. 